\title{
Towards generation of as-damaged BIM models using laser-scanning and as-built BIM: First estimate of as-damaged locations of reinforced concrete frame members in masonry infill structures
}

\author{
Reem Zeibak-Shini ${ }^{\Uparrow}$, Rafael Sacks, Ling Ma, Sagi Filin \\ Faculty of Civil and Environmental Engineering, Technion - IIT, Israel
}

\section{a rt icleinfo}

\section{Article history:}

Received 16 September 2015

Received in revised form 16 February 2016

Accepted 1 April 2016

\section{Keywords:}

BIM

Earthquake damage

Laser scanning

Reinforced concrete

Search and rescue

Structural frame

\begin{abstract}
a b s tract
After an earthquake, Terrestrial Laser Scanning (TLS) can capture point clouds of the damaged state of building facades rapidly, remotely and accurately. A long-term research effort aims to develop applications that can reconstruct 'as-damaged' BIM models of reinforced concrete (RC) framed buildings based on their 'as-built' BIM models and scans of their 'as-damaged' states. This paper focuses on a crucial step: generating an initial 'best-guess' for the new locations of the façade structural members. The output serves as the seed for a recursive process in which the location and damage to each object is refined in turn. Locating the 'as-built' structural members in the 'as-damaged' scan is challenging because each member may have different displacement and damage. An algorithm was developed and tested for the case of reinforced concrete frames with masonry infill walls. It exploits the topology of the frames to map the original structural grid onto the damaged façade. The tests used synthetic datasets prepared from records of two earthquake-damaged buildings. In both cases, the results were sufficiently accurate to allow progress to the following step, assessment of the individual structural members.
\end{abstract}

\section{Introduction}

Structural engineering expertise is essential in search and rescue (S\&R) and recovery operations in the aftermath of a major earthquake in an urban area. S\&R teams need information about voids that may have formed in buildings that have sustained damage in order to plan efforts to reach any survivors safely. In the recovery phase, structural engineers gather information to assess the state of the buildings and the degree of damage they have suffered.

To be effective, the information must be gathered rapidly. Yet in post-disaster situations professional structural engineers are a scarce resource and gathering the information is, in and of itself, a difficult and potentially hazardous activity. Under the standard protocols of most countries, in the immediate post-earthquake phase structural engineers inspect each building and classify it as safe, unsafe or dangerous [1-3]. This is laborious, slow and provides little of the detailed information needed.

\footnotetext{
$\Uparrow$ Corresponding author at: Faculty of Civil and Environmental Engineering, Technion Campus, Haifa 32000, Israel.

E-mail addresses: reemz@technion.ac.il, reemzeibak@gmail.com (R. Zeibak-Shini).
}

For these reasons, researchers have proposed the use of remote sensing techniques and sophisticated computing methods. One approach has been to provide surveyors on the scene with mobile applications for recording data, such as ROVER Ready [4] and Urban RAT [5]. These tools help surveyors record and transmit information, but they do not acquire information directly. Remote sensing technologies, such as laser scanning and photogrammetry, can be used to automate data acquisition and to rapidly provide point cloud and segmented geometry information describing the exterior forms of building components after an earthquake [7-9]. However, the point cloud and segmented face geometry cannot be analyzed in relation to the pre-existing building components without extensive interpretation and information about the building's original condition. Exterior scanning has two additional drawbacks: it lack the semantics needed for damage assessment of the exterior components and it provides no information at all concerning the interior components and spaces of the building.

However, much more detailed and useful information can be inferred if an 'as-built' model compiled using Building Information Modeling (BIM) [6] technology is used as the starting point for inference from the point cloud data. BIM models can provide the detailed information about buildings' 'as-built' states in the form of parametric object-oriented models with component, functional and other non-geometric information, and they can be used to 
store new information as it is acquired. This has been explored for the purposes of construction management, where systems attempt to estimate construction progress based on comparison of scan and image data with 'as-planned' BIM models $[10,11]$.

The authors propose a framework of steps and a suite of algorithms to process information from these two sources to generate useful structural engineering information for post-earthquake S\&R and recovery efforts. The overall method, described in Section 3 below, aims to generate an 'as-damaged' BIM model that contains both the external and internal components of a building, with both structural and building system components. The aim is to provide first responders with information that can guide their S\&R efforts, akin to 'x-raying' the damaged building. The information can also be used directly to assess the damage, first for structural assessment and later for estimating the costs of repair and/or for planning the demolition.

The framework as a whole requires six main modules. Details for modules 1 and 6 can be found in [12]. This paper focuses on module 3 of the framework, dealing with the challenge of reconstructing the BIM model of the exterior facade of a damaged building from the point cloud data. The authors developed and tested a procedure that prepares an initial estimate of the locations of the 'as-damaged' structural frame members on each façade using information from the 'as-damaged' scan and the 'as-built' BIM. The algorithm presented is specific to the case of reinforced concrete framed buildings with unreinforced masonry (URM) walls.

\section{Literature review}

\subsection{Remote sensing data acquisition for earthquake damage detection}

Airborne laser scanning technology is useful in post-earthquake phase for general damage identification at the detail level of the structure as a whole $[13,14]$. Terrestrial Laser Scanning (TLS) can provide more detailed damage information at a much higher resolution than aerial scanning, making it applicable for damage assessment on building elements. Lindenbergh and Pietrzyk [15] discussed applications in change and deformation detection using static and mobile TLS. Both static and mobile TLS were able to document the spatial geometry of a bridge in high accuracy [16].

A novel application of TLS for assessing damage to buildings dealt with tornado damage in the US [17]. The authors used point cloud data (PCD) acquired before and after an earthquake to evaluate how much damage was caused to each building. They were also able to estimate the path direction and the wind speed of the tornado by combining data for multiple buildings. Despite the progress made in recognition of building objects within PCD for generic construction management applications [11,18], neither Kashani et al. nor others who have applied TLS to earthquake damage assessment have attempted to compile parametric building models.

In addition to laser scanning, terrestrial video and photogrammetry technologies can also generate dense 3D point clouds of a scene using approaches such as 'Structure-from-Motion' systems [19], Multi-view Stereo methods [20], and others. Some examples:

- German et al. [7] successfully designed and implemented an algorithm to identify the cracks in concrete columns using video recordings.

- Torok et al. [21] used images obtained from an unmanned robotic platform to similarly identify cracks in the main structural members.

- Yamazaki et al. [22] used photos collected by Unmanned Aerial Vehicles (UAV) to generate a 3D model of a district damaged in the 2015 Gorkha earthquake in Nepal.
Some other applications in condition assessment of civil infrastructures are reviewed in [23]. However, none of the above attempted to reconstruct parametric building models at the level of detail of individual building components.

\subsection{Damage assessment and modeling}

A number of studies have focused on identifying and evaluating structural damage to exterior members by analyzing observed cracks and spalling data. To assess the performance of damaged reinforced concrete structures, Farhidzadeh et al. [24] proposed a crack related damage index that is capable of estimating specimens' relative stiffness loss. Paal et al. [25] proposed identification of cracking and spalling of reinforced concrete columns. Their work was later extended to compute the residual drift capacity of such columns [26,27]. Lattanzi et al. [28] applied photogrammetry techniques to identify cracks on bridge columns in structural tests. The feature data of the identified defects were further used to build a prediction model for maximum column drift.

Damage to structures may have causes other than earthquakes, of course, and TLS has been proposed for tasks such as bridge health/damage evaluation [29]. Examples include measuring the thickness of corroded gusset plates of collapsed I-35W Highway Bridge in Minneapolis, Minnesota [30] and deformation measurement of a Hungarian bridge on the Danube during its load testing procedure [31]. Tang and Akinci [32] formalized the workflow of manual procedures of processing PCD for bridge inspection to enable automation.

These studies demonstrate that the TLS methods can detect damage with high accuracy, but that the process depends on scans of the pre-event state. In case of a disaster, it is unlikely that a preevent scan of the studied area will be available so that the model might not be applicable in such circumstances. Furthermore, none of these efforts has attempted to reconstruct an 'as-damaged' BIM model.

\subsection{Scan to BIM - challenges in semantic interpretation}

The Scan-to-BIM process has been the subject of numerous studies. Tang et al. [33] surveyed techniques developed in civil engineering and computer science that can be utilized to automate the process of creating as-built BIMs. The authors sub-divided the overall process into three core operations: geometric modeling, object recognition, and object relationship modeling. They surveyed the state-of-the-art methods for each operation and discussed their potential application to automated as-built BIM creation. They also outlined the main methods used by these algorithms for representing knowledge about shape, identity, and relationships. Bosché et al. [34] explored the opportunity for frequent, detailed and semantically rich assessment of as-built status of MEP works in construction projects by joining three dimensional laser scanning and 3D/4D BIM models, and Sacks et al. [35] proposed an approach for semantic enrichment that supports object recognition and object relationship modeling.

Xiong et al. [36] presented a method to automatically identify and model the main visible building components of a scanned indoor environment (walls, floors, ceilings, windows, and doorways). The authors suggested extracting planar patches from a voxelized version of the raw point cloud. Their algorithm learns the unique features of different types of surfaces (vertical, horizontal, etc.) and the contextual relationships between them and uses this knowledge to automatically label patches as walls, ceilings, or floors. The authors also presented an opening detection algorithm to detect openings in building facades. They overcame the challenge of modeling partially occluded or occupied openings by 
learning a model of the typical size, shape, and location of openings from training examples. Their algorithm detects and models rectangular-shaped openings, which is the predominant shape in most buildings. It uses features computed from the occlusion labels and from depth edges to learn a model of openings using a support vector machine (SVM) classifier.

Nonetheless, the Scan-to-BIM process is still not considered a solved problem, because the scan only contains the geometry information, and automated compilation of a semantically rich BIM solely from the graphical model is very challenging. Semantic information can be inherited if an 'as-built' BIM is available, but the Scan-to-BIM task is even more challenging in case of damage occurrence, as the 'as-damaged' scan represents a different geometry of the same structure (e.g. openings can no longer be assumed to be rectangular-shaped features) and matching it with the 'asbuilt' is an additional hurdle.

\subsection{Skeletonization and model matching}

Research towards Scan-to-BIM can also draw on knowledge developed in computer science research concerned with matching models of different states of the same structure. The majority of this work is in the field of body motion and non-rigid structures. Skeletonization is a popular method to explore the topological structure of shapes. It is widely used in research of hand motion capture [37], in which a hand model is built as a set of rigid segments connected by a hierarchical configuration of joints. The joints have determinate rotational degrees of freedom (DoF) according to the physical constraints of a human hand; different rotational constraints are applied to different joints. The movement of a joint is represented as the rotation relative to its parent joint, up to the root joint, which is close to the wrist. Based on these kinematic features, given the parental joints' position, the position of the end effectors (ends of the fingers) can be identified. Alternatively, given the position of the end effectors, the movement of parental joints can also be estimated using an inverse kinematic method [37].

Research on matching different representations of the same object from images generally falls into one of two categories: Laplacian-based mesh-to-mesh matching for objects that are subjected to non-rigid body deformation $[38,39]$ and piecewise shapeto-shape matching for objects that are subjected to rigid body motion $[37,40]$. While rigid body motion may be suitable for initial representation of typical damage modes of reinforced concrete building components [41], building components can also break into pieces, and this obscures the shape-to-shape corresponding relationship. In addition, the damage propagation pattern of building components is not pre-determined, which makes piecewise matching unpredictable. Thus, none of the above methods is directly applicable to this problem.

Three relevant conclusions pertaining to earthquake S\&R and recovery operations are drawn from the literature review:

- The primary remote-sensing technologies available for acquiring information about earthquake-damaged buildings are terrestrial laser scanning and image processing through video- or photogrammetry.

- The data collected is insufficient for compilation of building information models that provide semantic information about the building's components. This requires BIM model data of the pre-event state, but this has not been attempted.

- None of the research efforts reviewed made any attempt to estimate the 'as-damaged' condition of the building's internal components.

\section{Overall system framework}

Considering the limitations of the state-of-the-art and the availability of BIM and laser-scanning technologies, we propose an approach that makes use of the pre-event BIM model in two ways: first, to support automated interpretation of the post-event point clouds and produce a BIM model of the damaged building's exterior facades; and second, to generate a large solution space of candidate collapsed building models from which the most-likely collapse model can be selected to predict the interior damage. The end result of the overall system is a BIM model that includes rich semantic information describing the exterior and the interior building components in their 'as-damaged' state.

Fig. 1 provides a high-level overview of the approach. The figure breaks the process into six main processing modules, each of which is described briefly below. Modules 1 and 6 are detailed in Bloch et al. [12]; Module 3 is the subject of this paper and is described in detail in the following sections.

In the first module, performed before a possible earthquake, a structural analysis 'collapse engine' software is used to generate a large database of possible damaged or collapsed building models. The 'as-built' BIM provides the input of the building's structural components and of any building system components that might influence the structural behavior. A range of ground motions and directions are used to attempt to provide broad coverage of the range of possible cases. Given that time is not specifically limited, in practice extremely large solution sets can be generated and stored.

The second module begins in the immediate aftermath of the earthquake with laser-scanning or photogrammetry of the damaged or collapsed building. Scanning is performed within a short time, and provides point clouds registered in the relevant local cadastral coordinate system (the same system in which the 'asbuilt' BIM model is registered). The point clouds are then segmented using commonly available algorithms to identify planar surfaces.

Modules 3, 4 and 5 are run recursively, adding new BIM objects to the 'as-damaged' model until all of the external 'as-built' BIM objects have been matched to point cloud segments or determined to be missing, in whole or in part (i.e. they have been destroyed, damaged or they are occluded from the scans). Module 3 identifies the structural grid, defined in the as-built BIM, in the as-damaged point cloud data, resulting in an initial estimate of the new locations and orientations of the structural frame members.

In Module 4 the goodness-of-fit between pairs of scan segments and the 'expected faces' of BIM objects is evaluated. The 'expected faces' are aggregations of the contiguous surfaces of 'as-built' BIM objects that may be expected to appear as segments in the point clouds, such as occurs when reinforced-concrete components are cast monolithically with one another and they have continuous and adjacent (coplanar) exterior surfaces. In each iteration cycle, the pair with the best fit is used: the location of cracks or breaks on the BIM objects is determined, and a new 'as-damaged' representation of the original BIM object is generated within Module 5. The new object is added to the 'as-damaged' BIM model and the process flow returns to the location estimation step (Module 3), which is now based on a more accurate set of starting data.

In the sixth module, a matching algorithm based on minimum distances is applied to evaluate the goodness of fit of each of the candidate collapse models (generated in Module 1) to the 'asdamaged' BIM model. The model with the best fit is selected to support search and rescue operations. Finally, for the recovery operations, the 'as-damaged' model can be compared directly with the 'as-built' model to support quantification of the damage. 

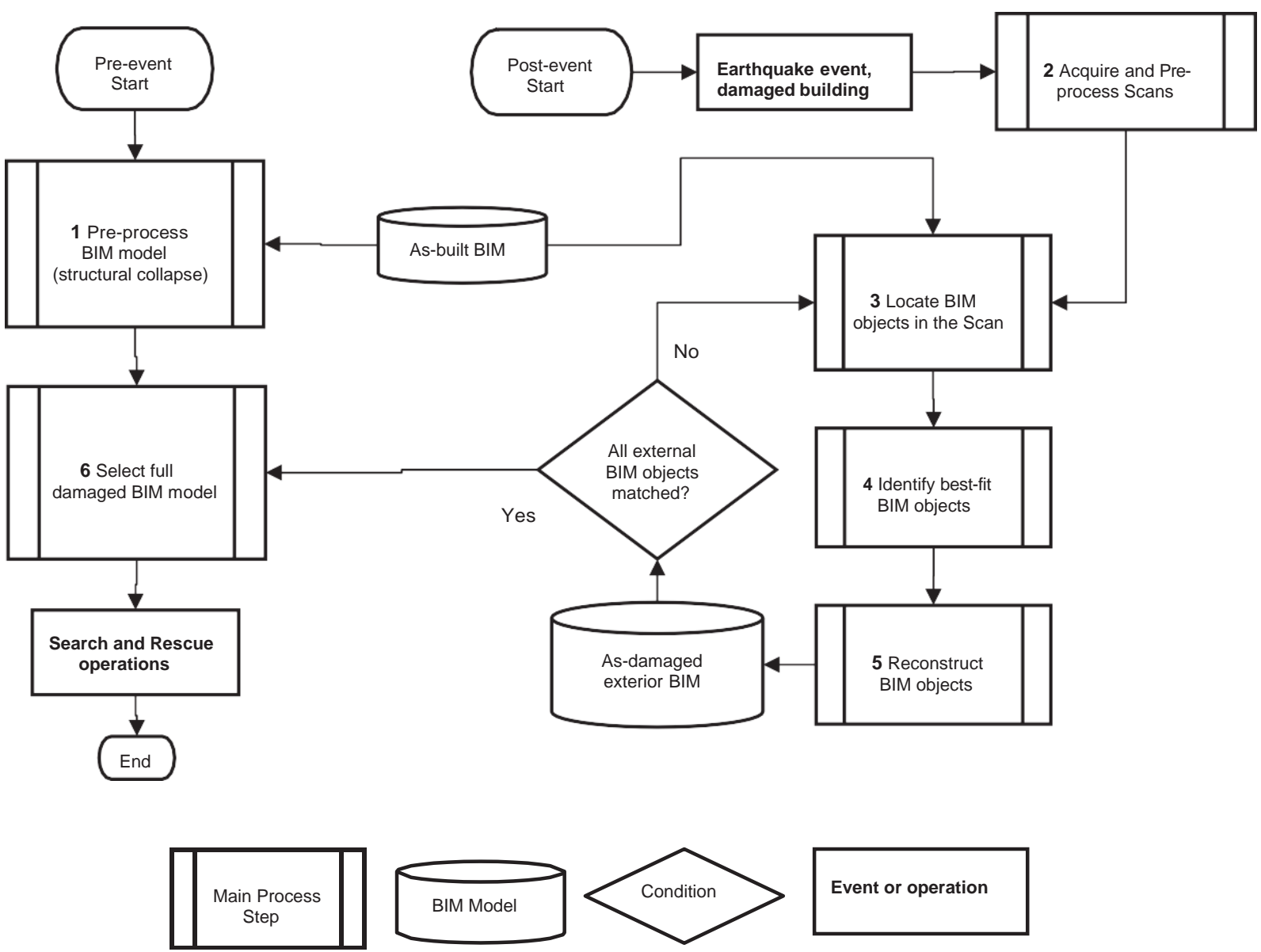

Event or operation

Fig. 1. System overview.

4. Scope - building type and damage mode

\subsection{RC framed buildings with URM infill walls}

In terms of building structure, this research focuses on reinforced concrete (RC) framed buildings with unreinforced masonry (URM) infill walls. RC framed structures are the most common structure type for multi-story buildings in many countries [42]. A typical frame unit of this kind of structure consists of two beams (top and bottom), two columns (left and right) and a panel of infilled masonry, as shown in Fig. 2. The structural grid can be characterized as four linear segments (representing the four structural members) connected by four box-shaped beam-column

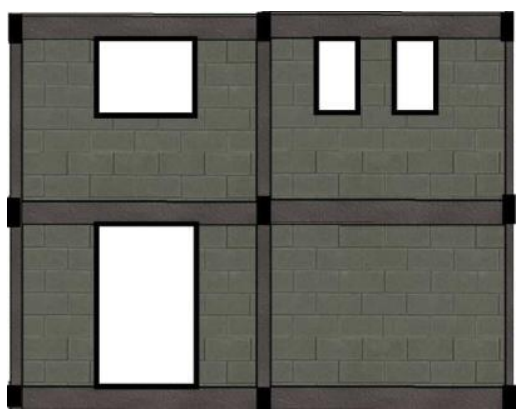

(a) joints. As the next sub-section explains, this characterization of the joints is useful for damage representation as structural members tend to shear on or near the planes of the joints.

The structural frame of the exterior facades can be considered as a grid composed of cells. The structural cells consist of beams, columns, joints and any URM infill between them. A structural cell may or may not contain voids in the infill. The cells can be aggregated as bays (vertically) or as floors (horizontally).

\subsection{Damage modes considered}

Liel and Lynch [43] categorized earthquake damage types on RC framed buildings with URM infills into five states: 'Negligible',

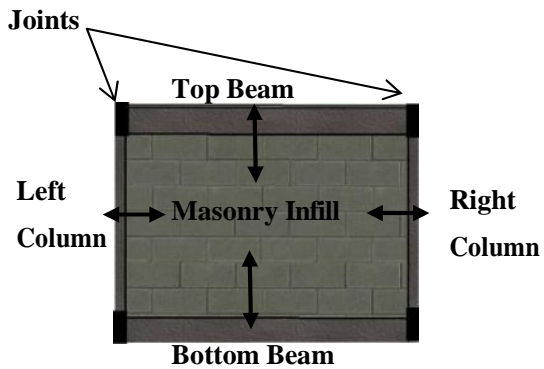

(b)

Fig. 2. (a) RC framed buildings with URM infills. (b) A structural cell within the building frame and its members' topological configuration. 
'Insignificant', 'Moderate', 'Heavy', 'Collapse'. This research studies RC framed buildings with URM infills that have undergone moderate to heavy damage. The 'collapse' damage state is not considered.

Damage such as structural failure of beams and columns or outof-plane failure of URM infills is considered. Total collapse of the building or its parts in case of a soft story where RC members are totally demolished is outside the research scope. However, partial collapse of stories as a result of short-column failures is considered within scope. Structural failures in beams and columns are more likely than failure within the volumes of the joints. Joints might move or rotate, whereas beams or columns tend to break at their interface with the joints or within their lengths.

After an earthquake, the masonry may collapse out-of-plane partially or completely, creating new voids or enlarging existing voids. In the majority of cases, the top edges of new and/or preexisting voids align with the bottom face of the top beam, because masonry walls require beams or lintels above openings and because masonry infills always collapse downwards. The beams and columns may be bent or sheared, but in most cases the topological relationships between the columns and the URM/void space remains unchanged. Fig. 3 shows some typical examples of the kinds of damage that are considered.

As will be seen, these features can be leveraged to support matching the as-built and as-damaged models. The approach described in the next section exploits these geometrical, topological and behavioral features of RC frames with URM infills to identify an initial estimate of the damaged structural grid by mapping the as-built grid onto the as-damaged scan.

\section{Proposed procedure}

The goal of the procedure described here and in the test cases in Section 6 (module 3 of the overall system detailed in Fig. 1) is to generate an initial estimate of the exterior structural frame of the damaged building, as a "best guess" of the location and orientation of concrete elements in the scan. The flowchart presented in Fig. 4 outlines the procedure. The identities and dimensions of all RC elements forming the structural frame are read from the asbuilt BIM. This information includes the distances between columns and between beams and the number of bays and floors in the façade. The matching and mapping procedure is done in three automated steps:

(1) map the original structural grid of each façade onto the range image of that façade using its boundary extents and linear interpolation for all interior axes,

(2) improve accuracy by adjusting the horizontal grid axes to align their segments with the top edges of the voids identified in the range image in each cell,
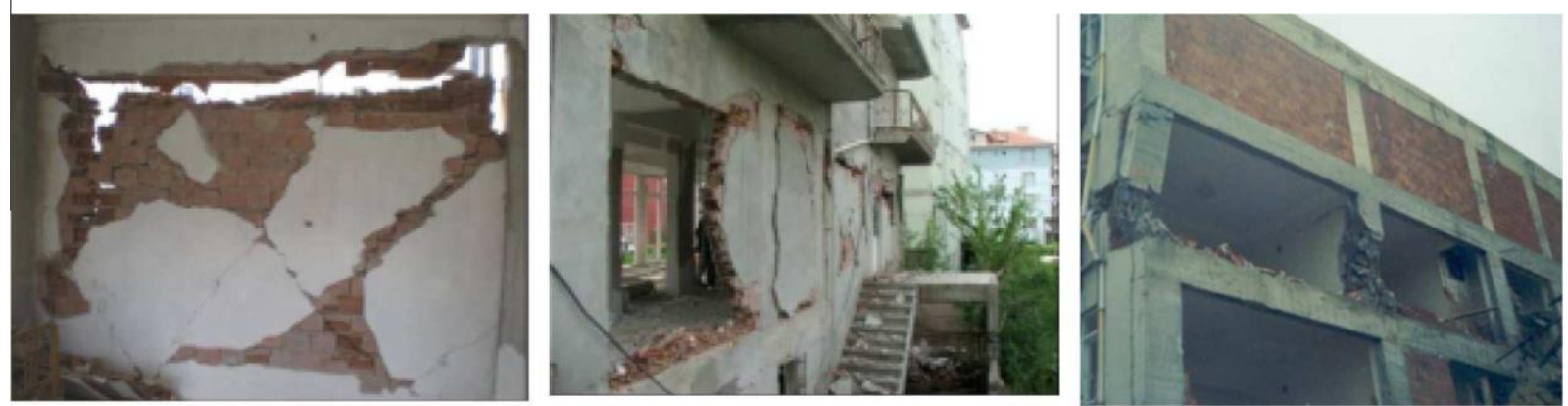


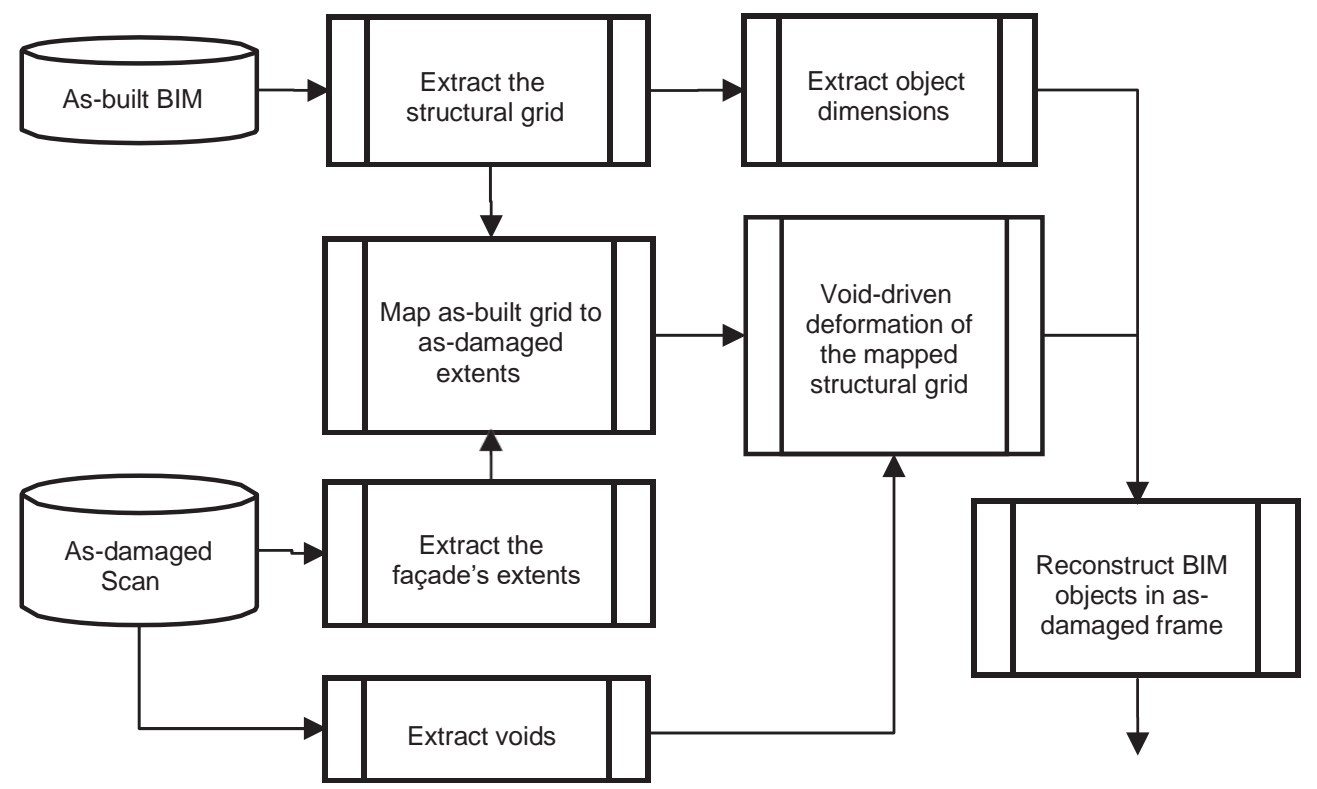

Initial estimate of the damaged façade BIM
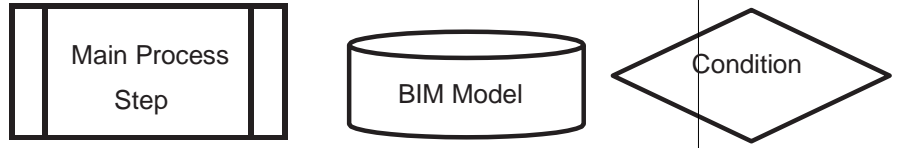

\section{Event or operation}

Fig. 4. Flowchart of Module 3, for locating BIM objects in the scan.

inputs for the procedure, including the full 'as-built' BIM models and synthetic point clouds of the damaged buildings, were prepared using the methods and software detailed in Ma et al. [44]. The outputs are BIM models of the as-damaged state of each building in IFC format. To validate the procedure, the outputs were compared to the original pre-prepared 'as-damaged' models.

As will be seen in the case studies that follow, mapping the structural grid of the original structure onto the as-damaged scan is fairly straightforward for buildings with moderate damage, but significantly more challenging for the case of heavy damage. Although for the case of moderate damage it would seem that the latter step - mapping using voids to identify the structural grid - might be considered superfluous, the proposed procedure does not differ with respect to damage severity.

\subsection{Case 1: Kocaeli residential building - moderate damage}

The first case study is a residential building damaged in a magnitude 7.6 earthquake in Kocaeli, Turkey, on August 17th 1999. The information regarding this building before and after the earthquake was obtained from the EERI database [45]. To begin with, a complete 'as-built' BIM model was prepared in Tekla Structures 20.0 using the 2D drawings and other information regarding the building components available in the EERI website, and exported as an IFC file.

Next, a model of the damaged building façade was prepared by a modeler by clipping and displacing the structural elements according to the evidence provided by the available photographs (such as Fig. 5). Fig. 6(a) shows the façade modeled in the BIM software. The model was then scanned using laser scanning emulation

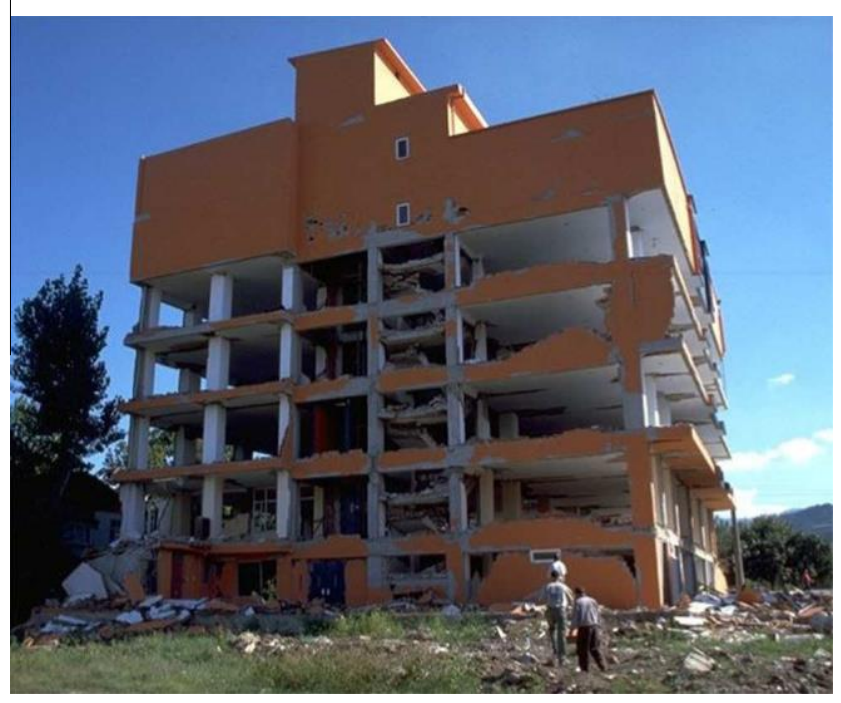

Fig. 5. A photograph of a façade of the Kocaeli residential building [45].

software with an angular resolution of $0.02^{\circ}$, yielding a point cloud of some 700,000 points (Fig. 6b). Thus, this model served two purposes: it represents the ground truth for the experiment and it is the source data for scanning, since no laser scans of the real damaged building were available. Details of the procedure for preparing the synthetic data is provided in Ma et al. [44].

The virtual scanner was positioned directly in front of the selected façade of the building, viewing only that façade. Using 


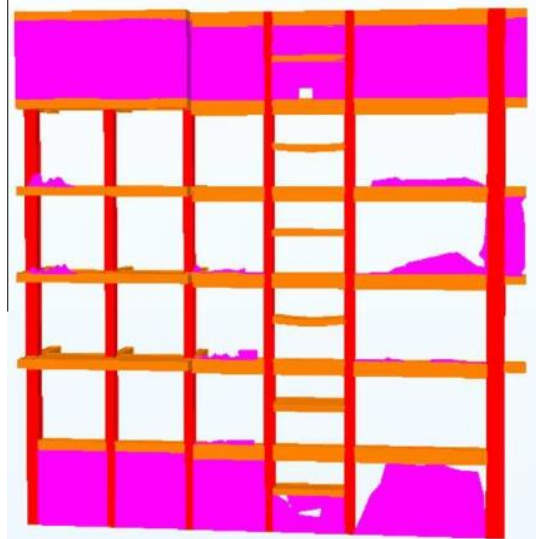

(a)

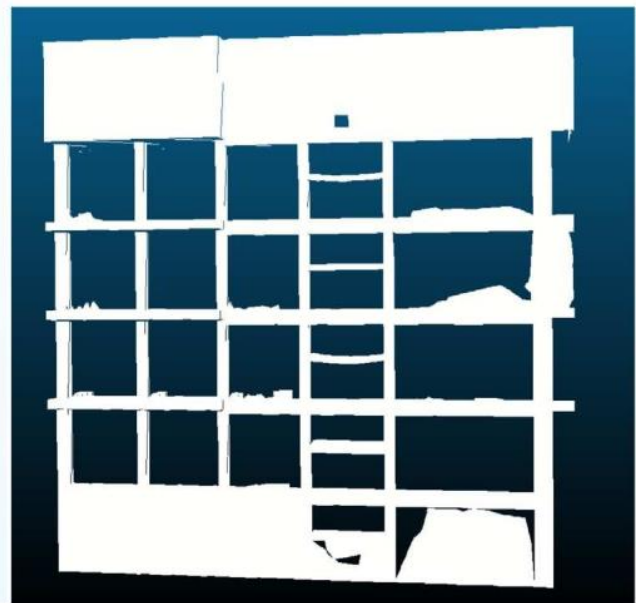

(b)

Fig. 6. The as-damaged façade: (a) user prepared BIM model; (b) simulated laser-scan point cloud.

the same scanner viewport, all components visible to the scanner were then extracted from the as-built BIM IFC file (Fig. 7a). Next, the beams and columns that form the structural frame were filtered from that file (Fig. 7b) and the floors, bays and structural grid cells were identified and labeled. The dimensions of the beams and columns and of the grid itself were also extracted from the as-built BIM.

The structural cells are readily identifiable in the as-built BIM model, because the beams and columns are modeled explicitly. On the other hand, the structural cells in the 'as-damaged' scan cannot be identified easily because the texture-less building façade (with plaster on the surface) makes it difficult to distinguish the beams, columns and infills within the façade because their exterior surfaces are all coplanar. The following paragraph details the reconstruction of the 'as-damaged' structural frame for this building using the procedure outlined in Section 5 above.

First, for the sake of efficient data processing, the point cloud is converted into a range image (a significantly more compact data representation) (Fig. 8a). The range image represents the point cloud in a spherical coordinate system rather than the Euclidean system. The first pass attempt to determine the new locations of the beams and columns in the as-damaged state is achieved by proportional scaling and mapping of the as-built grid into the

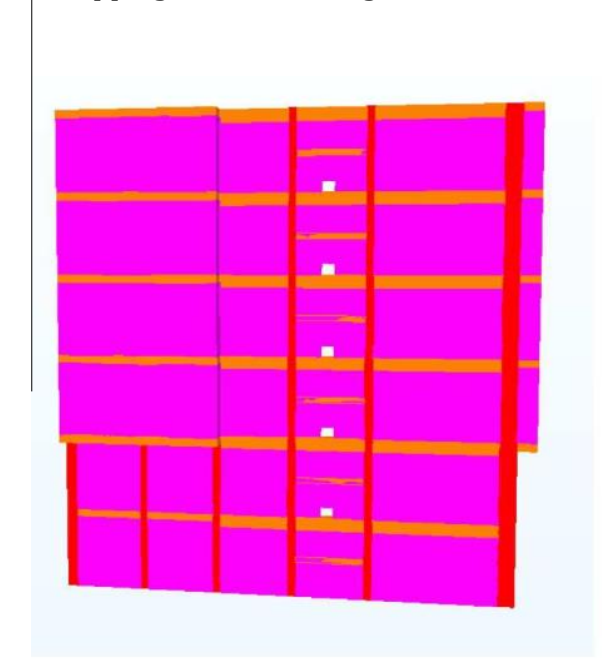

(a) range image. The grid's four corners are identified in the range image as control points for the mapping procedure. All other intermediate cell corners along the outer boundary of the grid are approximated in the scan using linear interpolation to keep the same relative division into the same number of bays and floors. Intersections between gridlines connecting those interpolated points define the interior cell corners. Connecting all interpolated corners results in a scaled mapping of the as-built grid onto the range image (Fig. 8b).

Where damage is heavy, however, this mapping is unlikely to be adequate. Beams and columns might bend or break in some of the structural cells, reducing their height and distorting their rectangular shapes. The proportionally scaled as-built grid is an imperfect skeleton of the damaged building because it is insensitive to the internal geometric changes the façade may have undergone. Instead, its gridlines must be deformed to follow key features that represent the new geometry.

Voids within URM infills provide distinct features within damaged cells and are the key to a better mapping. The masonry infill walls are prone to collapse as a result of natural disasters, thus forming new voids or merging existing ones. Three main possible cases might occur: voids in the 'as-damaged' model represent 'asbuilt' openings (with or without change in geometry and size);

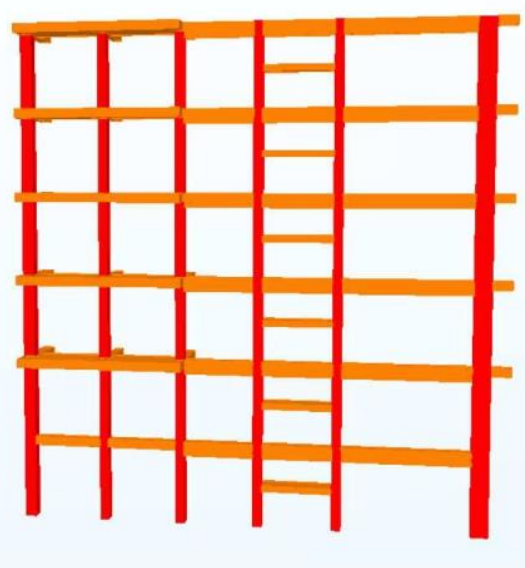

(b)

Fig. 7. The as-built façade: (a) RC structural frame model with URM infills; (b) RC structural frame without infills. 


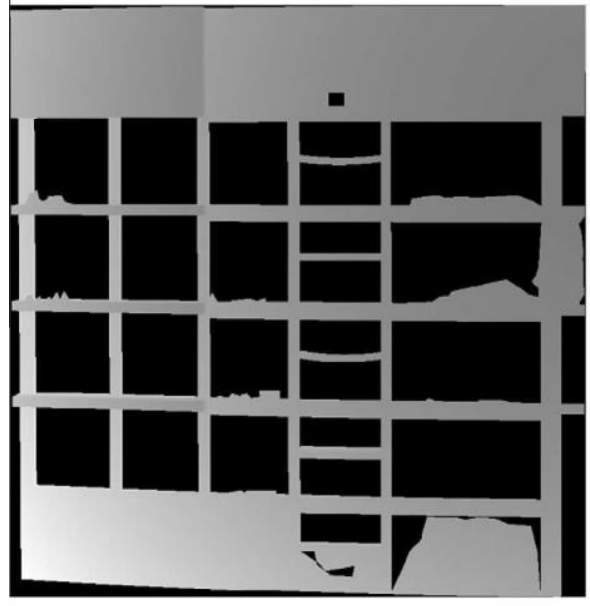

(a)

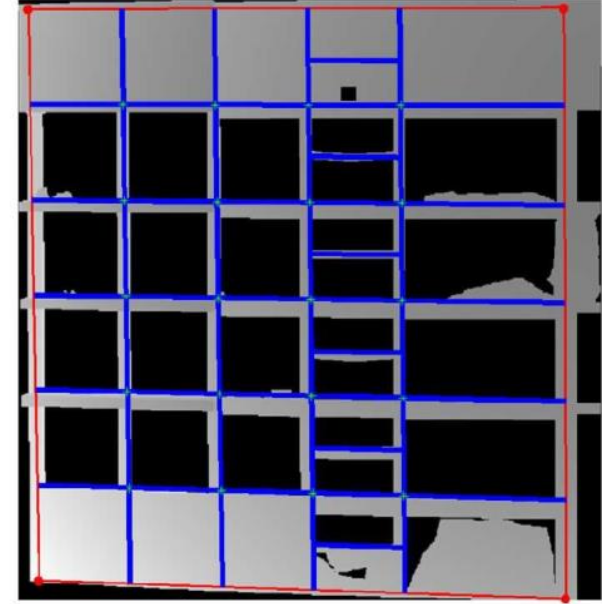

(b)

Fig. 8. (a) Range image of the 'as-damaged' scan; (b) first pass mapping of the as-built structural grid (blue) onto the as-damaged range image. (For interpretation of the references to colour in this figure legend, the reader is referred to the web version of this article.)

neighboring 'as-built' voids within the same cell are merged; or, new voids are created as a result of collapse of masonry. In all three cases the voids reveal the lower edge of the upper beam in each cell. Identification of voids' top edges can help locate the beams and consequently other structural members of the cell connected to it, thus deriving a form topologically similar in configuration to the as-built grid.

The voids can be extracted by tracing the boundaries of "noreturn" regions in the range image of the scan (Fig. 9a). The topleft, top-right, bottom-left and bottom-right corners of each void are determined using its bounding box, which in turn defines the top, bottom, right and left sides of the void (Fig. 9b).

Each damaged structural cell may contain more than one void and the correspondence between voids and structural cells is not obvious because the sources of the voids are unknown. To overcome this apparent problem, the scaled grid serves as a first guess to associate voids to their corresponding cells by overlapping the scaled gridlines with the void regions. The correspondence is derived based on criteria of overlapping area between voids and cells from the scaled grid. Very small voids (with an area smaller than a threshold value) are neglected.

Table 1 shows the association results and percentage of maximum overlap between the voids and the associated cells in the façade of the Kocaeli residential building. Each void was associated with the cell with which it had the highest proportion of overlapping area. For this building, 29 voids were associated with 36 cells. Manual inspection of the results showed $100 \%$ success of the association. The numbering schemes are shown in Fig. 10.

The new base levels of damaged beams are derived by extending and connecting the top edges of the identified voids belonging to the same cell, as is shown in Fig. 11. Each of the resulting polylines is then shifted upwards by the beam's height (which is known explicitly from the 'as-built' BIM) to determine the top levels of the beams. Where no voids exist in a cell, the polylines of neighboring cells are extended to locate the joints and the beams are assumed to connect those joints. This makes the default assumption (for lack of any information at this stage other than the observation that the masonry infill in the cell is apparently intact) that the earthquake

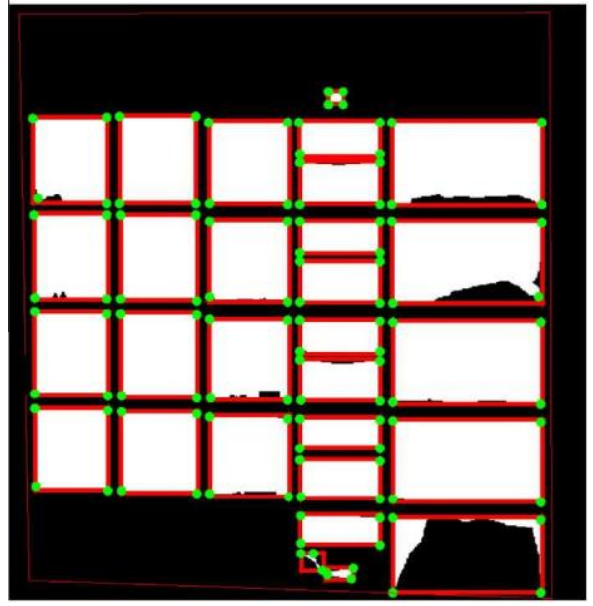

(a)

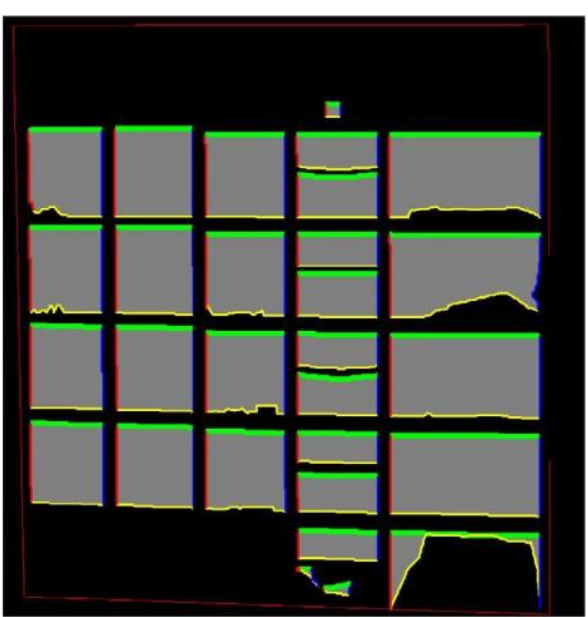

(b)

Fig. 9. (a) Bounding box and four corners of the 'as-damaged' voids in the range image. (b) Bottom, top, right and left sides of the voids in yellow, green, blue and red respectively. (For interpretation of the references to colour in this figure legend, the reader is referred to the web version of this article.) 
Table 1

Void to cell association using maximum proportional overlapping area.

\begin{tabular}{rlr}
\hline Void ID & Cell ID & Max. overlap\% (threshold 50\%) \\
\hline 5 & {$[1]$} & 100.0 \\
15 & {$[2]$} & 100.0 \\
17 & {$[2]$} & 100.0 \\
14 & {$[3]$} & 100.0 \\
4 & {$[7]$} & 98.2 \\
13 & {$[8]$} & 93.6 \\
12 & {$[9]$} & 100.0 \\
18 & {$[10]$} & 98.4 \\
22 & {$[11]$} & 97.4 \\
27 & {$[12]$} & 98.8 \\
3 & {$[13]$} & 98.5 \\
11 & {$[14]$} & 93.8 \\
10 & {$[15]$} & 99.0 \\
21 & {$[16]$} & 98.5 \\
24 & {$[17]$} & 97.7 \\
26 & {$[18]$} & 98.2 \\
2 & {$[19]$} & 99.9 \\
9 & {$[20]$} & 99.0 \\
8 & {$[21]$} & 100.0 \\
20 & {$[22]$} & 99.6 \\
23 & {$[23]$} & 99.4 \\
28 & {$[24]$} & 99.6 \\
1 & {$[25]$} & 100.0 \\
7 & {$[26]$} & 100.0 \\
6 & {$[27]$} & 100.0 \\
19 & {$[28]$} & 100.0 \\
25 & {$[29]$} & 100.0 \\
29 & {$[30]$} & 100.0 \\
16 & {$[32]$} & 100.0 \\
\hline & &
\end{tabular}

induced motion has not deformed the beam above that cell nor disconnected it from the joints.

The positions of beam-column joints are estimated based on the beam and column widths extracted from the 'as-built' BIM and on the positions of the damaged beams in all the structural cells. The center axes of the columns in each cell are estimated by connecting these joints. The resulting first estimate of the structural grid of the damaged building is shown in Fig. 12a.

The refined beam gridlines represent the estimated top edges of the as-damaged beams, and the column gridlines locate the centerlines of the as-damaged columns. Using the as-built dimensions and the resulting as-damaged grid, the beams, columns and joints were finally placed in their new estimated locations and orientations. This is done by defining a Local Reference Frame (LRF) on each gridline, such that the origin is located at the center point of the grid line, the $X$ direction is along the grid line, and the $X Z$ plane is parallel to the global façade plane (i.e. zero axial rotation is assumed). Each beam and column is thus placed with its center of gravity placed at its associated LRF, its major axis lies along the LRF $X$ axis, and it is not rotated about the major axis.

Finally, given that each 'as-damaged' member is already associated with it corresponding 'as-built' member, all of the alphanumeric property data are inherited accordingly.

\subsection{Case 2: Bingol school building - heavy damage}

The second case study is a school building damaged in a magnitude 6.4 earthquake in 2003 in Bingol, Turkey, which sustained heavy damage, as can be seen in the photograph shown in Fig. 13a. In addition to the collapse of most of the URM infill walls, a soft story collapse occurred and the first floor of the building pancaked. Many beams and columns were heavily damaged, undergoing translation and rotation and some columns had sheared. The information regarding this building before and after the earthquake was obtained from the EERI database [46]. Fig. 13b shows the BIM model prepared from the drawings.

As explained in Sections 5 and 6, the same procedure is followed. The text that follows therefore presents the steps for the Bingol case study without repeating the details (see Fig. 14)

The simulated scan was performed with approximately the same point of view as the as-damaged photograph (Fig. 13a), viewing two of the building's façades in angular resolution of $0.02^{\circ}$. The point cloud contained some 740,000 points. Fig. 15 presents the point cloud in spherical coordinate system as a range image.

The BIM model was filtered first to remove elements that were outside the scan point of view or completely occluded (Fig. 16a), and secondly to leave only RC structural frame members (Fig. 16b). The structural grid, with three bays and three floors on each of two façades, was identified from the as-built model.

On the other hand, the overall boundary of the damaged building's facades can be derived based on the extent of the 'asdamaged' scan. Due to the partial collapse of the ground floor in the case study building, the overall height is smaller than it was before the damage. Thus, the 'as-built' structural grid is used proportionally to divide the 'as-damaged' scan into initial cells, as shown in Fig. 17.

Note that the initial gridding of the scan did not match the new damaged structural frame of the building due to the soft story collapse, where the original proportions of floors' height was not conserved. Therefore, in this case, identifying the voids in the asdamaged scan was essential for improving the mapped grid. The

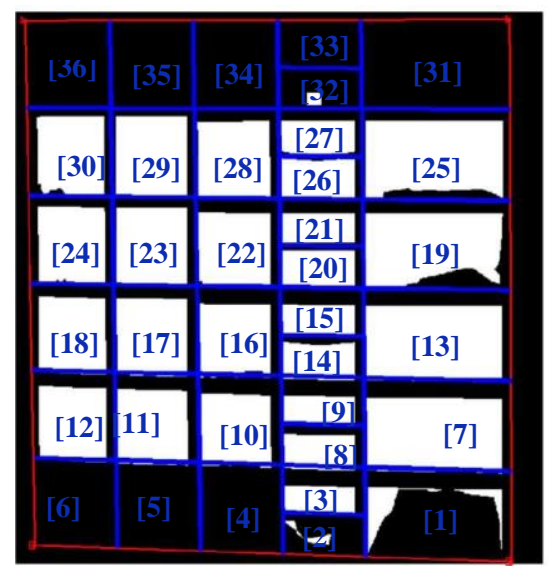

(a)

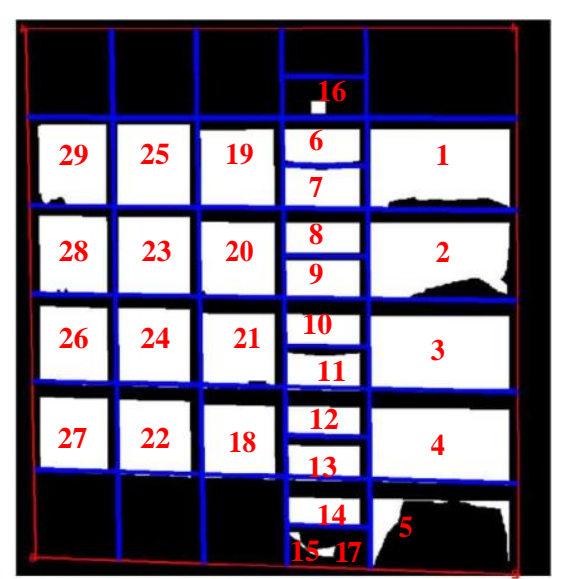

(b)

Fig. 10. (a) Cell numbering; (b) void numbering. 


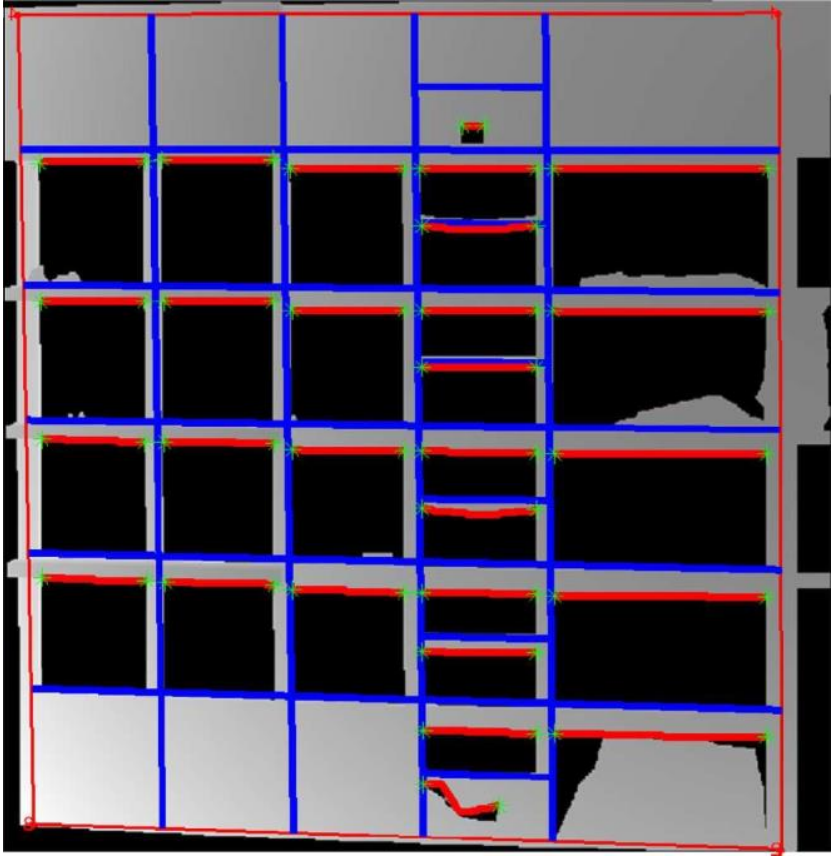

Fig. 11. Identification of voids' top edges in each structural cell.

voids and their top edges were identified in the range image, as can be seen in Fig. 18.

Table 1 shows the association results and percentage of maximum overlap between the voids and the associated cells. In summary, $75 \%$ (15 out of 20 ) of the voids are wholly contained within their corresponding cells. The remaining voids each extend over more than one cell. In this case study building, using a threshold of $50 \%$ overlap for association, all 20 voids were associated with 18 cells (see Fig. 16 and Table 2). As for the Kocaeli case study, manual inspection of the results showed $100 \%$ success for the association (see Fig. 19).

Where more than one void occurred in a single cell, all of the top edges of the voids were linked with straight line segments to form a polyline. This polyline represents the best estimate of the new location of the bottom edge of the upper beam in the cell. The grid was then relocated according to the polylines in the same way as described in Section 6.1 above. The new end points of the vertical gridlines were established by assuming that the endpoints of the beam axes of adjacent cells were equidistant from the new column centerlines, as they were in the as-built state (i.e. joint zones are not deformed). Fig. 20 shows the deformed and refined versions of the initial grid that represents the as-damaged structural frame.

As for case 1, the refined beam gridlines represent the estimated top edges of the as-damaged beams, and the column gridlines locate the centerlines of the as-damaged columns. The result is shown in Fig. 21. Finally, as before, the LRF is defined for each gridline, the corresponding members are placed accordingly, and the alphanumeric data is copied.

\subsection{Performance}

The procedure described above was programmed using Matlab 7.12.0 and run on a computer with Intel ${ }^{\circledR}$ core $^{\mathrm{TM}} \mathrm{i} 5 \mathrm{CPU}$ processor. The total runtime for each case study (including scan processing, void extraction, grid mapping, void-to-cell association, gridline deformation and reconstruction of the beams and columns) was on the order of magnitude of $2 \mathrm{~min}$. This runtime is very short in relation to the scanning itself and will therefore not detract from the feasibility of the system in the aftermath of an earthquake.

\section{Verification}

The output of the procedure is an IFC file containing the structural members of the façades in their best-estimated locations and orientations, yet with their original cross-section shapes and lengths. Thus the mapping derived at this point is only an initial estimate of the damaged state that will be refined through recursive iteration of the solution process as a whole (as defined in Section 3 and illustrated as steps 4 and 5 in Fig. 1, and beyond the scope of this paper). The outputs for both buildings were verified by visual inspection of the number of members correctly placed and by the use of Boolean geometry operations to measure the overlapping volumes of the output and the benchmark asdamaged models that were prepared by the researchers. The overlapping volumes were used to calculate the degrees of precision and of recall.

Fig. 22 shows the output BIM model, the original as-damaged BIM model prepared by the researchers, and a superposition of

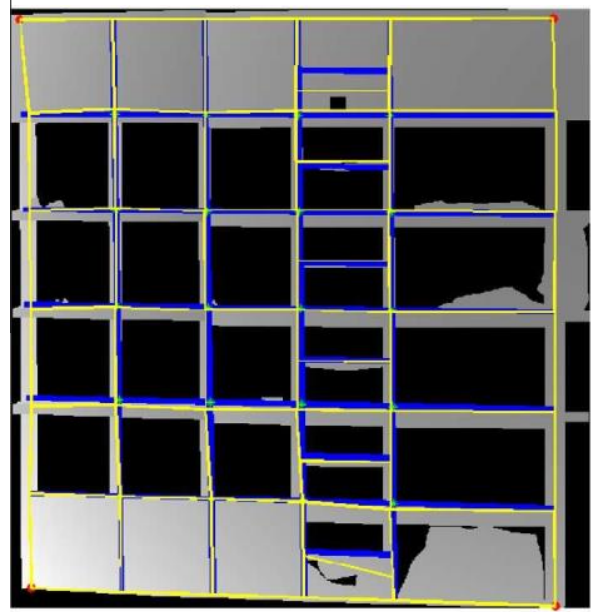

(a)

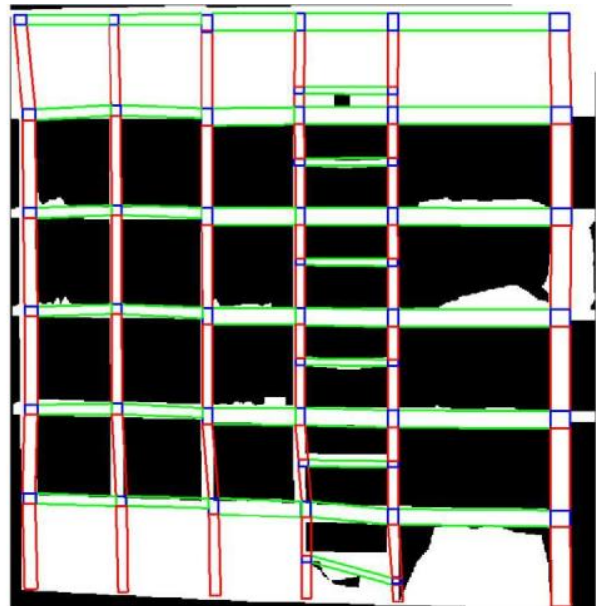

(b)

Fig. 12. (a) Refinement of the initial damaged skeleton (initial skeleton in blue, refined skeleton in yellow); (b) reconstructing the as-damaged RC frame (beams in green, columns in red and joints in blue). (For interpretation of the references to colour in this figure legend, the reader is referred to the web version of this article.) 


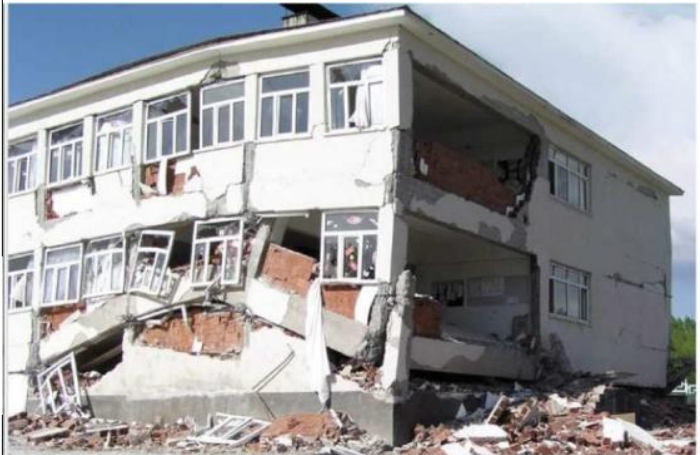

(a)

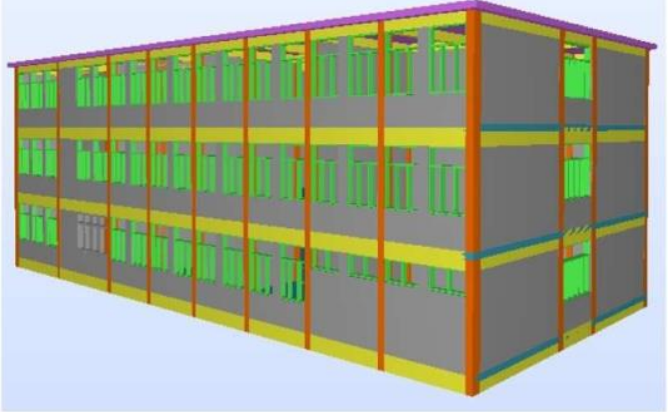

(b)

Fig. 13. (a) A photograph of a corner of the damaged Bingol school building [46]; (b) as-built BIM model of the building.

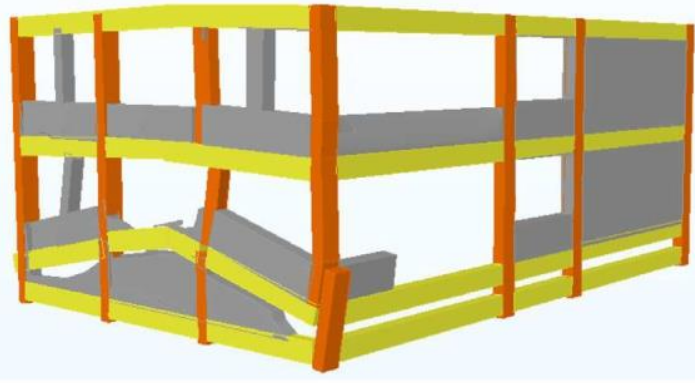

(a)

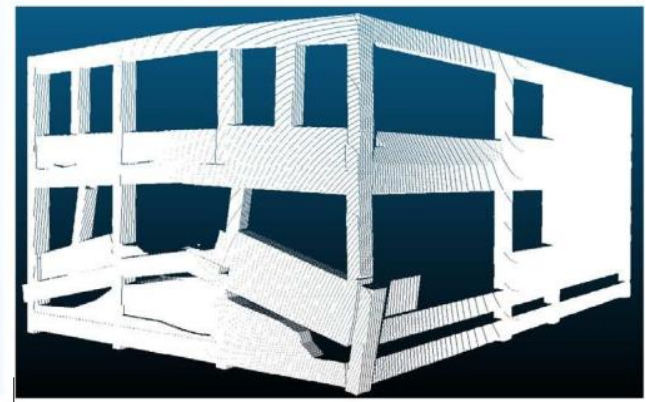

(b)

Fig. 14. As-damaged state: (a) user pre-prepared BIM model; (b) scanned point cloud.

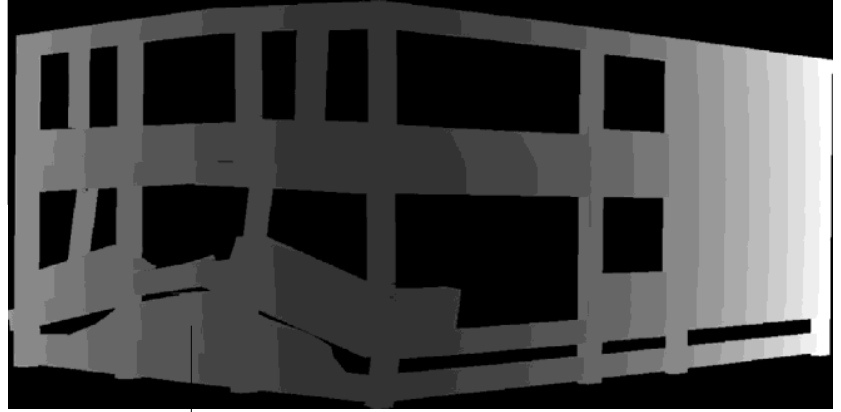

Fig. 15. Range image of the as-damaged scan. Gray scale represents range values distant points are lighter, darker points are closer to the viewer. Black pixels represent no-data.

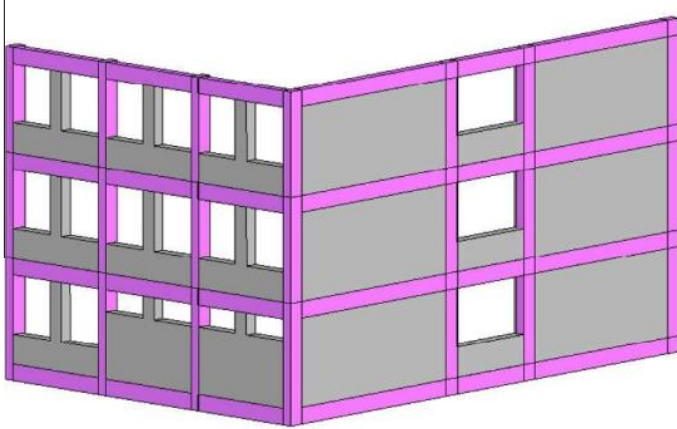

(a)

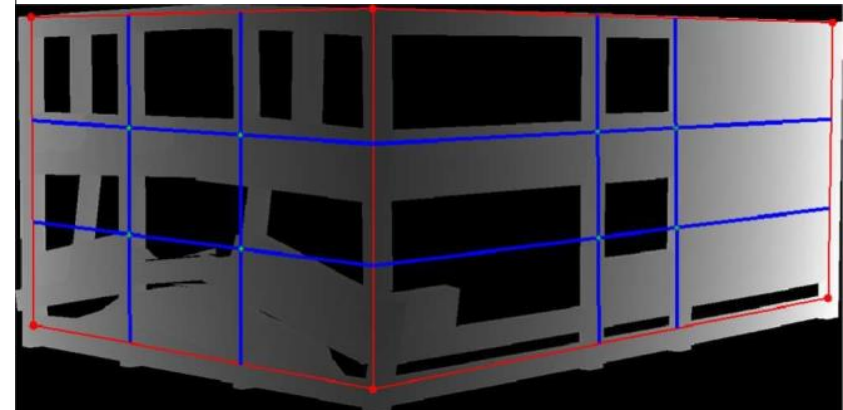

Fig. 17. Initial cells in the 'as-damaged' scan derived by scaling and mapping the 'asbuilt' grid onto the range image (in blue). (For interpretation of the references to colour in this figure legend, the reader is referred to the web version of this article.)

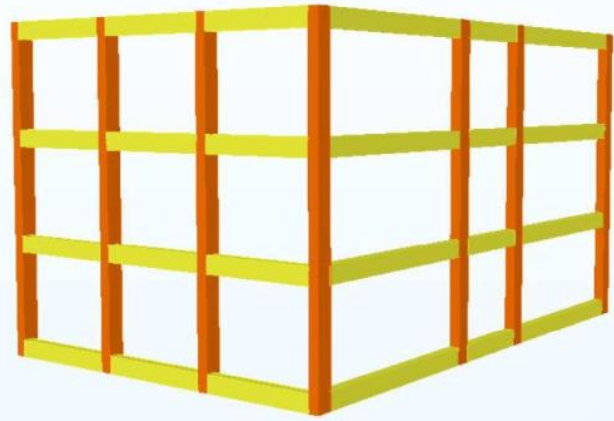

(b)

Fig. 16. The 'as-built' model: (a) RC frame with URM infills. (b) RC structural frame with beams and columns only. 


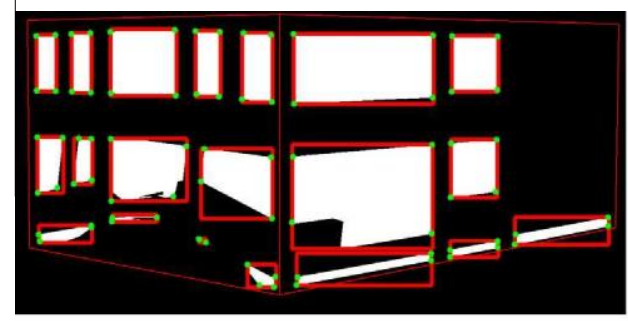

(a)

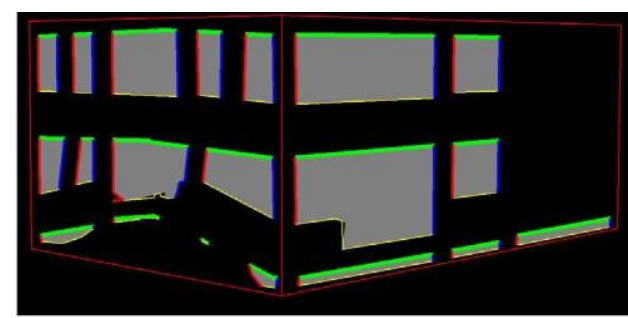

(b)

Fig. 18. (a) Bounding boxes and corners of the voids in the range image. (b) Bottom, top, right and left sides of the voids in yellow, green, blue and red respectively. (For interpretation of the references to colour in this figure legend, the reader is referred to the web version of this article.)

Table 2

Void to cell association based on maximum overlapping percentage.

\begin{tabular}{rlc}
\hline Void ID & Cell ID & Max. overlap\% (threshold 50\%) \\
\hline 1 & {$[1]$} & 100.0 \\
2 & {$[2]$} & 100.0 \\
3 & {$[14]$} & 100.0 \\
4 & {$[8]$} & 92.4 \\
5 & {$[15]$} & 100.0 \\
6 & {$[9]$} & 66.5 \\
7 & {$[3]$} & 100.0 \\
8 & {$[4]$} & 100.0 \\
9 & {$[16]$} & 100.0 \\
10 & {$[10]$} & 99.6 \\
11 & {$[4]$} & 100.0 \\
12 & {$[16]$} & 100.0 \\
13 & {$[11]$} & 94 \\
14 & {$[17]$} & 100.0 \\
15 & {$[5]$} & 100.0 \\
16 & {$[18]$} & 100.0 \\
17 & {$[12]$} & 100.0 \\
18 & {$[6]$} & 100.0 \\
19 & {$[12]$} & 90.9 \\
20 & {$[18]$} & 100.0 \\
\hline
\end{tabular}

the two models. Visual inspection shows that for the Kocaeli residential building 70 out of 72 structural components were identified correctly. Two mid-story beams that support the staircase landings were placed incorrectly. This error results from the fact that the beams are not located directly above the small openings below them, as the procedure assumes. This type of error might be overcome in the future by identifying such special situations and applying a change detection procedure to infills and voids. A cell that consists of the same geometry of infills and openings after the event will be reconstructed using the same proportional relationships as the original.

Similar inspection of the results for the Bingol school building shows that 42 out of 45 structural components were identified correctly. As can be seen in Fig. 22c, some of the columns in the first floor have sheared and their resulting parts overlap one another along part of their length. However, the procedure models them with their original lengths. Reconstruction of the columns including identification of any breaks and other distortions of their shapes is the subject of the next step in the overall system (Module 4 in Fig. 1) and beyond the scope of this paper.

The overlapping volume for each building, representing the 'true positive' (TP) result, was computed by first performing a Boolean union of all of the beams and columns in each model (output and pre-prepared benchmark) and then a Boolean intersection of the two resulting solids. The false negative (FN) is the volume of the benchmark model that remains when the output model is subtracted from it (i.e. the portion of the true result that was not identified correctly). Similarly, the false positive (FP) is the volume of the output model that remains when it is subtracted from the benchmark model. Precision measures the proportion of the true result that was predicted correctly and is computed as $\mathrm{TP} /(\mathrm{TP}+\mathrm{FP})$, whereas Recall measures how much of the output was accurate and is computed as $\mathrm{TP} /(\mathrm{TP}+\mathrm{FN})$.

The results of the Boolean operations and of the Precision and Recall calculations are provided in Table 3. As expected, predicted positive and the actual positive values for the Koaceli residential building (case 1) are similar because both the output and the benchmark models contain the same structural RC members and damage is slight. This is not the case for the Bingol school building, because some of the parts of the heavily damaged columns have been grossly displaced. Nevertheless, the results for precision

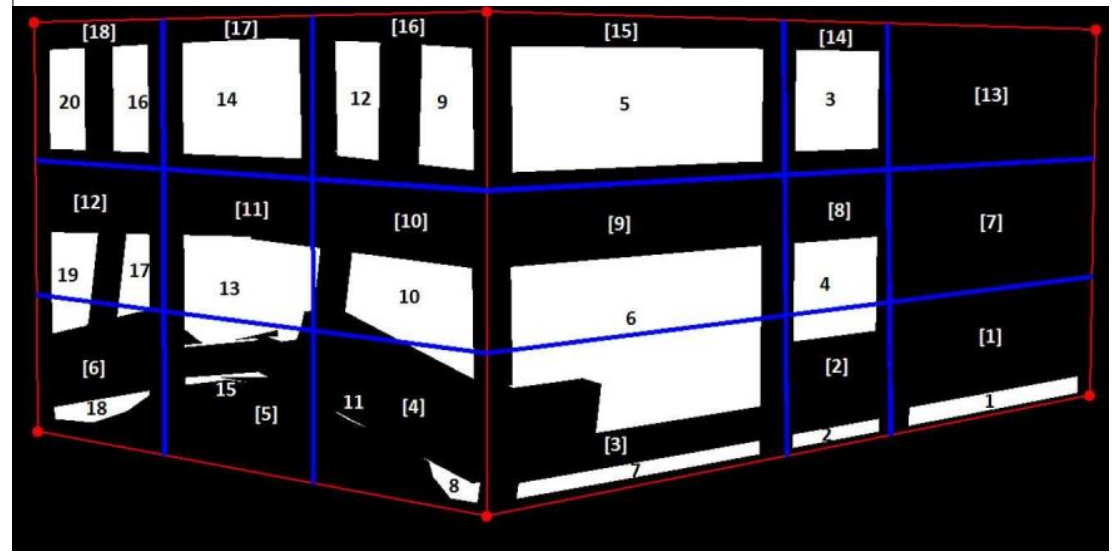

Fig. 19. Void numbering (no brackets) and cell numbering (in brackets). 


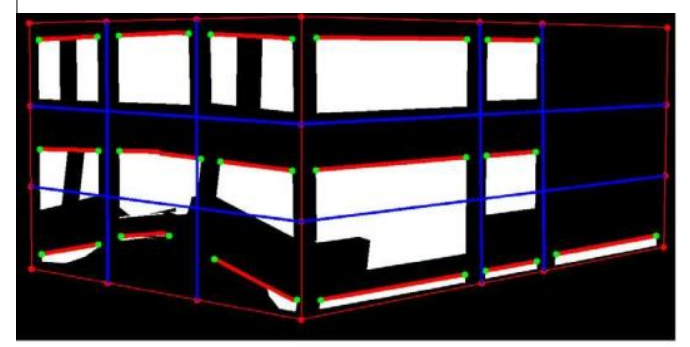

(a)

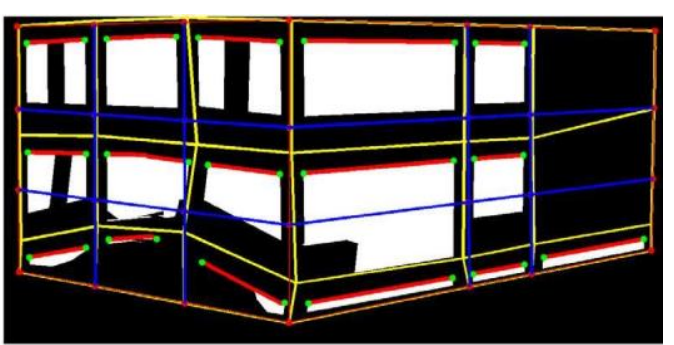

(b)

Fig. 20. (a) Identification and linkage of voids' top edges in each structural cell; (b) resulting structural grid (initial skeleton in blue, refined skeleton in yellow). (For interpretation of the references to colour in this figure legend, the reader is referred to the web version of this article.)

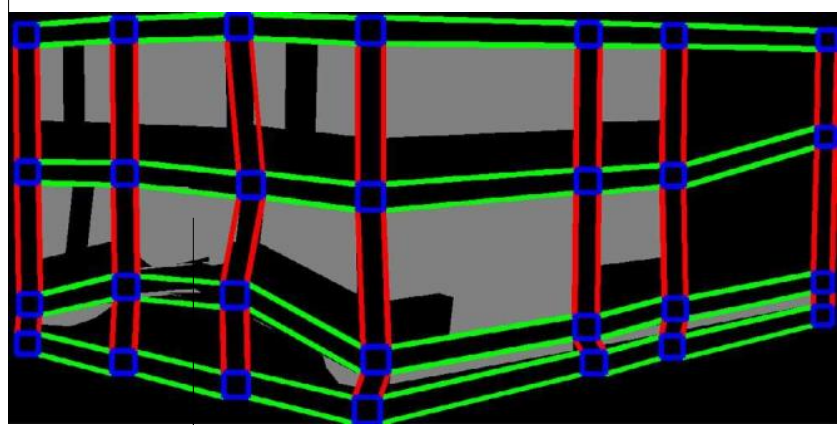

Fig. 21. Reconstructed as-damaged RC frame (beams in green, columns in red). (For interpretation of the references to colour in this figure legend, the reader is referred to the web version of this article.)
( $81.98 \%$ and $76.57 \%$ respectively for the two buildings) confirm that the procedure is relatively successful at preparing the first estimate for the overall process. Success is determined by the ability of the procedure to identify at least one member's new location well enough to allow the next steps, in which the shape of each member will be refined to better fit the real as-damaged shape as reflected in the PCD. In both cases, more than one member was very well matched, thus surpassing this requirement.

\section{Conclusion}

A new, methodical procedure for performing the first step of a method for reconstructing a semantically rich BIM model of the asdamaged state of an RC framed structure that has been dam- aged by an earthquake has been developed and tested. The proce-
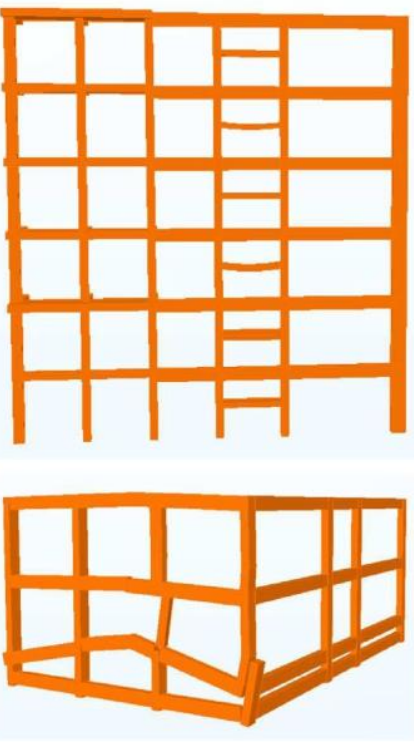

(a)
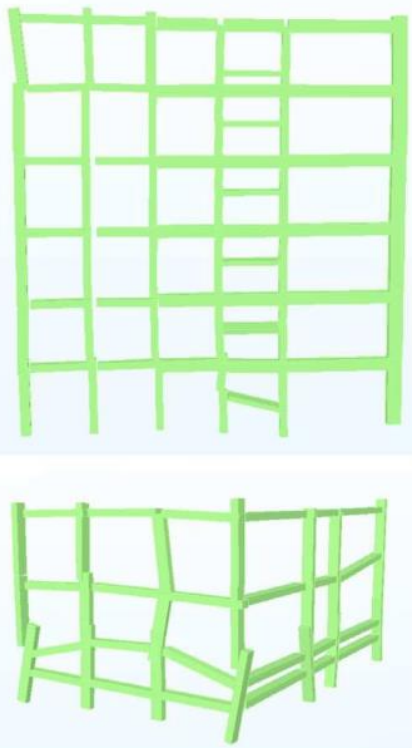

(b)
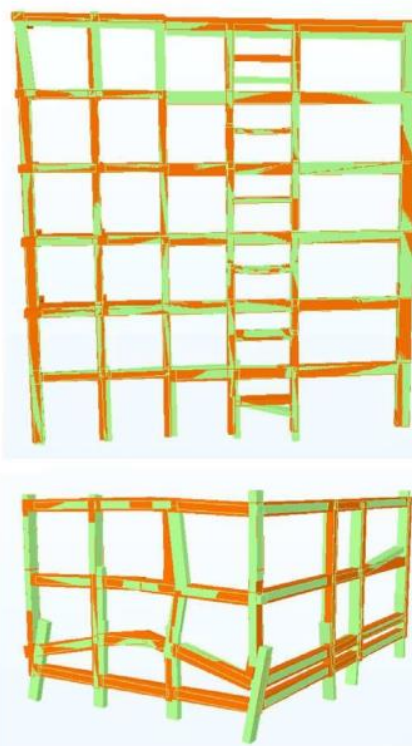

(c)

Fig. 22. Case 1 (top row) and Case 2 (bottom row): (a) Pre-prepared as-damaged model (without infills). (b) Process output - reconstructed as-damaged model. (c) Superposition of the two models (pre-prepared and reconstructed).

Table 3

Precision and recall results for the two case studies.

\begin{tabular}{|c|c|c|c|c|c|c|c|}
\hline Case & $\begin{array}{l}\text { True Positive } \\
(\mathrm{TP})\left(\mathrm{m}^{3}\right)\end{array}$ & $\begin{array}{l}\text { False Positive } \\
(\mathrm{FP})\left(\mathrm{m}^{3}\right)\end{array}$ & $\begin{array}{l}\text { False Negative } \\
(\mathrm{FN})\left(\mathrm{m}^{3}\right)\end{array}$ & $\begin{array}{l}\text { Predicted positive } \\
(\mathrm{TP}+\mathrm{FP})\left(\mathrm{m}^{3}\right)\end{array}$ & $\begin{array}{l}\text { Precision TP/ } \\
(\mathrm{TP}+\mathrm{FP})(\%)\end{array}$ & $\begin{array}{l}\text { Actual positive } \\
(\mathrm{TP}+\mathrm{FN})\left(\mathrm{m}^{3}\right)\end{array}$ & $\begin{array}{l}\text { Recall TP/ } \\
(\mathrm{TP}+\mathrm{FN})(\%)\end{array}$ \\
\hline Kocaeli & 34.13 & 7.49 & 8.12 & 41.62 & 81.98 & 42.25 & 80.77 \\
\hline Bingol & 18.75 & 5.74 & 5.19 & 24.49 & 76.57 & 23.94 & 78.35 \\
\hline
\end{tabular}


dure's success in locating most of the members correctly for both the moderate and the heavy damage cases strongly suggests that development of a methodical procedure for the first phase of reconstruction of semantically rich BIM models of damaged building façades using TLS is a feasible and promising approach to support planning of S\&R and recovery operations after a natural disaster. Two major problems have been tackled in this solution: the lack of any semantic information in the scan and the need to match the original structural members with the displaced and/or damaged objects that are present in the point cloud data.

The procedure serves as the first module in a broader S\&R support system these problems. In this procedure the 'as-built' BIM model is essential for providing information defining the building's components. A set of rational assumptions concerning the specific geometry, topology and behavior of URM infilled RC frame were necessary to facilitate the methods' steps, which include extracting voids from the scan, mapping the voids to the structural cells, and reconstruction of the structural grid of the damaged building.

Application of the proposed approach to two case studies of RC framed buildings damaged in the 1999 Kocaeli Earthquake (Case 1) and in the 2003 Bingol Earthquake (Case 2) in Turkey, showed good and satisfactory results. However, situations where columns and beams might shear and bend cannot be identified by the method because of the explicit simplifying assumption, within the current scope, of rigid body motion.

Damage modes like members overlapping, out of plane damage of structural building members, etc., must therefore be identified in module 4 of the overall system, which uses local segmentation of the 'as-damaged' scan to identify cracks and breakages in individual members. In this way the modules will be deployed recursively to refine the model of the damaged building façade. In addition, more cases of damaged buildings will need to be tested to seek evidence for robustness of the procedure for Module 3 and of the system as a whole.

\section{Acknowledgments}

This research was funded in part by the Insurance Companies Association of Israel. The assistance of undergraduate research assistants Ashrant Aryal and Jiashu Liang is greatly appreciated.

\section{References}

[1] S. Anagnostopoulos, M. Moretti, Post-earthquake emergency assessment of building damage, safety and usability - Part 1: Technical issues, Soil Dynam. Earthquake Eng. 28 (2008) 223-232.

[2] FEMA, Evaluation of Earthquake Damaged Concrete and Masonry Wall Buildings: Basic Procedures Manual-FEMA 306, Federal Emergency Management Agency, 1988.

[3] S. Okada, N. Takai, Classifications of structural types and damage patterns of buildings for earthquake field investigation, Presented at the Proceedings of the 12th World Conference on Earthquake Engineering (paper 0705), Auckland, 2000.

[4] S. Hunter, L. Kohandoust, H. Schechner, R. Bakerian, Rapid Observation of Vulnerability and Estimation Risk (ROVER), Applied Technology Council, 2013.

[5] S. Ploeger, M. Sawada, A. Elsabbagh, M. Saatcioglu, M. Nastev, E. Rosetti, Urban RAT: new tool for virtual and site-specific mobile rapid data collection for seismic risk assessment, J. Comput. Civ. Eng. (2015) 04015006.

[6] C.M. Eastman, P. Teicholz, R. Sacks, K. Liston, B.I.M. Handbook, A Guide to Building Information Modeling of Owners, Managers, Designers, Engineers and Contractors, 2nd ed., John Wiley and Sons, Hoboken, NJ, 2011.

[7] S. German, J. Jeon, Z. Zhu, C. Bearman, I. Brilakis, R. DesRoches, L. Lowes, Machine vision-enhanced post-earthquake inspection, J. Comput. Civ. Eng. 27 (6) (2013) 622-634.

[8] C. Schweier, M. Markus, Classification of collapsed buildings for fast damage and loss assessment, Bull. Earthq. Eng. 4 (2) (2006) 177-192.

[9] L.G. Dong, J. Shan, A comprehensive review of earthquake-induced building damage detection with remote sensing techniques, ISPRS J. Photogramm. 84 (2013) 85-99.

[10] F. Bosche, Plane-based registration of construction laser scans with 3D/4D building models, Adv. Eng. Inform. 26 (1) (2012) 90-102.
[11] F. Bosche, C.T. Haas, Automated retrieval of 3D CAD model objects in construction range images, Automat. Constr. 17 (2008) 499-512.

[12] T. Bloch, R. Sacks, O. Rabinovitch, Interior models of earthquake damaged buildings for search and rescue, Adv. Eng. Inform. 30 (1) (2016) 65-76.

[13] P.L. Dong, H.D. Guo, A framework for automated assessment of postearthquake building damage using geospatial data, Int. J. Remote Sens. 33 (1) (2012) 81-100.

[14] W. Liu, P.L. Dong, J.B. Liu, H.D. Guo, Evaluation of three-dimensional shape signatures for automated assessment of post-earthquake building damage, Earthquake Spectra 29 (3) (2013) 897-910.

[15] R. Lindenbergh, P. Pietrzyk, Change detection and deformation analysis using static and mobile laser scanning, Appl. Geomat. 7 (2) (2015) 65-74.

[16] NDT documentation and evaluation of the roman bridge of lugo using GPR and mobile and static LiDAR, J. Perform. Constr. Facil. 29 (1) (2015) 06014004.

[17] A. Kashani, P. Crawford, S. Biswas, A. Graettinger, D. Grau, Automated tornado damage assessment and wind speed estimation based on terrestrial laser scanning, J. Comput. Civ. Eng. (2014) 04014051.

[18] I. Brilakis, M. Lourakis, R. Sacks, S. Savarese, S. Christodoulou, J. Teizer, A. Makhmalbaf, Toward automated generation of parametric BIMs based on hybrid video and laser scanning data, Adv. Eng. Inform. 24 (2010) 456465.

[19] M.J. Westoby, J. Brasington, N.F. Glasser, M.J. Hambrey, J.M. Reynolds, 'Structure-from-Motion' photogrammetry: a low-cost, effective tool for geoscience applications, Geomorphology 179 (2012) 300-314.

[20] Y. Furukawa, J. Ponce, Accurate, dense, and robust multiview stereopsis, IEEE Trans. Pattern Anal. Mach. Intell. 32 (8) (2010) 1362-1376.

[21] M. Torok, M. Golparvar-Fard, K. Kochersberger, Image-based automated 3D crack detection for post-disaster building assessment, J. Comput. Civ. Eng. 28 (5) (2014) A4014004.

[22] F. Yamazaki, T. Matsuda, S. Denda, W. Liu, Construction of 3D Models of Buildings Damaged by Earthquakes using UAV Aerial Images.

[23] C. Koch, Z. Zhu, S.G. Paal, I. Brilakis, Machine vision techniques for condition assessment of civil infrastructure, in: Z. Liu, H. Ukida, P. Ramuhalli, K. Niel (Eds.), Integrated Imaging and Vision Techniques for Industrial Inspection, Springer, London, 2015, pp. 351-375.

[24] A. Farhidzadeh, E. Dehghan-Niri, A. Moustafa, S. Salamone, A. Whittaker, Damage assessment of reinforced concrete structures using fractal analysis of residual crack patterns, Exp. Mech. 53 (9) (2013) 1607-1619.

[25] S.G. Paal, J. Jeon, I. Brilakis, R. DesRoches, Automated damage index estimation of reinforced concrete columns for post-earthquake evaluations, J. Struct. Eng. (2014) 04014228.

[26] S. German, I. Brilakis, R. DesRoches, Rapid entropy-based detection and properties measurement of concrete spalling with machine vision for postearthquake safety assessments, Adv. Eng. Inform. 26 (4) (2012) 846-858.

[27] Z. Zhu, S. German, I. Brilakis, Visual retrieval of concrete crack properties for automated post-earthquake structural safety evaluation, Automat. Constr. 20 (7) (2011) 874-883.

[28] D. Lattanzi, G. Miller, M. Eberhard, O. Haraldsson, Bridge column maximum drift estimation via computer vision, J. Comput. Civ. Eng. (2015), http://dx.doi. org/10.1061/(ASCE)CP.1943-5487.0000527. 04015051.

[29] W. Liu, S. Chen, E. Hauser, LiDAR-based bridge structure defect detection, Exp. Tech. 35 (6) (2011) 27-34.

[30] NTSB, Highway Accident Report: Collapse of I-35W Highway Bridge, Minneapolis, Minnesota, August 1, 2007, Highway Accident Report NTSB/ HAR08/03, National Transportation Safety Board Records Management Division, Washington, DC, 2007, p. 2008.

[31] T. Lovas, Á. Barsi, A. Detrekoi, L. Dunai, Z. Csak, A. Polgar, A. Berenyia, Z. Kibedy, K. Szocs, Terrestrial laserscanning in deformation measurements of structures, Int. Arch. Photogramm. Remote Sens. 37 (2008) B5.

[32] P.B. Tang, B. Akinci, Formalization of workflows for extracting bridge surveying goals from laser-scanned data, Automat. Constr. 22 (2012) 306-319.

[33] P. Tang, D. Huber, B. Akinci, R. Lipman, A. Lytle, Automatic reconstruction of as built building information models from laser-scanned point clouds: a review of related techniques, Automat. Constr. 19 (7) (2010) 829-843.

[34] F. Bosché, A. Guillemet, Y. Turkan, C. Haas, R. Haas, Tracking the built status of MEP Works: assessing the value of a scan-vs-BIM system, J. Comput. Civ. Eng. 28 (4) (2014) 05014004.

[35] M. Belsky, R. Sacks, I. Brilakis, Semantic enrichment for building information modeling, Comput. Aided Civ. Infrastr. Eng. (2015).

[36] X. Xiong, A. Adan, B. Akinci, D. Huber, Automatic creation of semantically rich 3D building models from laser scanner data, Autom. Constr. 31 (2013) 325337.

[37] A. Aristidou, J. Lasenby, Motion capture with constrained inverse kinematics for real-time hand tracking, in: 4th International Symposium on Communications, Control and Signal Processing (ISCCSP), 2010, 2010, pp. 1-5.

[38] C. Stoll, Z. Karni, C. Rössl, H. Yamauchi, H.-P. Seidel, Template deformation for point cloud fitting, Presented at the Proceedings of the 3rd Eurographics/IEEE VGTC Conference on Point-Based Graphics, 2006, pp. 27-35.

[39] M. Ye, X. Wang, R. Yang, L. Ren, M. Pollefeys, Accurate 3D pose estimation from a single depth image, in: 2011 IEEE International Conference on Computer Vision (ICCV), 2011, pp. 731-738.

[40] D. Smeets, J. Keustermans, J. Hermans, D. Vandermeulen, P. Suetens, Featurebased piecewise rigid registration in 2-D medical images, in: 2012 9th IEEE International Symposium on Biomedical Imaging (ISBI), 2012, pp.696-699. 
[41] L. Ma, R. Sacks, R. Zeibak-Shini, Information modeling of earthquake-damaged reinforced concrete structures, Adv. Eng. Inform. (2015).

[42] P. Haldar, Y. Singh, D.K. Paul, Identification of seismic failure modes of URM infilled RC frame buildings, Eng. Fail. Anal. 33 (2013) 97-118.

[43] Abbie B. Liel, Kathryn P. Lynch, Vulnerability of reinforced-concrete-frame buildings and their occupants in the 2009 L'Aquila, Italy, earthquake, Nat. Hazards Rev. 13 (1) (2012) 11-23.
[44] L. Ma, R. Sacks, R. Zeibak-Shini, A. Aryal, S. Filin, Preparation of synthetic asdamaged models for post-earthquake BIM reconstruction research, J. Comput Civ. Eng. (2015) 04015032 .

[45] EERI, Ilgi Moble Building. [Online] Available: <http://db.concretecoalition.org/ building/135>2014 (accessed 07.10.14).

[46] EERI, Turkey School Bldgs - Moment Frames. [Online] Available: <http:// db.concretecoalition.org/building/132>2014 (accessed 07.10.14). 